\title{
Лизакова P.A.
}

Барановичский государственный университет,

Барановичи, Беларусь.

e-mail: roza.gomel@yandex.by

Резюме: В статье рассматриваются фракторы, влияющие на сокращение абитуриентов в ВУЗы Беларуси на экономические фракультеты, предлагаются с целью усиления конкурентных преимуществ отдельно взятого ВУЗа рекомендации по использованию стратегии позиционирования, основанные на маркетинге персональных компетенций.

Ключевые слова: вуз, Беларусь, экономическая специальность, позиционирование, Интернет-маркетинг профессиональных компетенций.

Для цитирования: Лизакова Р.А. Проблемы белорусских вузов при формировании набора абитуриентов на экономические специальности // Развитие образования. - 2019. - № 3 (5). - C. 45-47. DOI:10.31483/r-33268

\section{Problems of belarusian universities in the formation of a set of applicants for economic specialties}

\author{
Roza A. Lizakova \\ Baranovichi State University, \\ Baranovichi, Belarus. \\ e-mail: roza.gomel@yandex.by
}

\begin{abstract}
The article discusses the factors affecting the decrease of applicants to Universities of Belarus at economic faculties, recommendations for using positioning strategies, based on marketing personal competences are offered with the purpose of strengthening competitive advantages of individual university.

Keywords: university, Belarus, economic specialty, positioning, Internet marketing of professional competences.

For citation: Lizakova R.A. (2019). Problems of belarusian universities in the formation of a set of applicants for economic specialties. Razvitie obrazovaniya = Development of education, 3(5), 45-47. (In Russ.) DOI:10.31483/r-33268.
\end{abstract}

\section{Беларусь вузӗсен экономика специальнос̧ӗсене абитуринтсем илнӗ чухнехи йывӑрлӑхӗсем}

Лизакова P.A.

Барановичи патшалӑх университече̌н,

Барановичи, Беларусь.

e-mail: roza.gomel@yandex.by

Аннотаци: Статьяра Беларусь вузе̌сен экономика фракультече̌сене ке̌рекен абитуриентсен йышӗ чакнин салтаве̌сене пӑхса тухнӑ. Пе̌р-пӗр вузӑн конкуренцире с̧е̌нтерме юрӑхлӑ пахалӑхне вӑйлатас те̌ллевпе уйрӑм специалист компетенцине маркетинг картинче позицировани стратегийе̌пе усӑ курса кӑтартма ку е вӑл се̌нў панӑ.

Тӗп сӑмахсем: вуз, Беларусь, экономика специальнос̧е̌, позицировани, професси компетенцийе̌н Интернет-маркетинге̌.

Для цитирования: Лизакова Р.А. Проблемы белорусских вузов при фрормировании набора абитуриентов на экономические специальности // Развитие образования. - 2019. - № 3 (5). - C. 45-47. DOI:10.31483/r-33268

$\mathrm{H}$ а сегодняшний день ситуация в Беларуси с набором абитуриентов, с точки зрения количественных показателей, имеет отрицательную тенденцию, которая сохранится фактически до 2025 г., т.к. только с 2007 г. в республике пойдет увеличение рождаемости. В 2010 году белорусские вузы приняли 100,5 тыс. студентов. Постепенно этот показатель снижался, в 2018 году на первый курс было зачислено всего 58,8 тыс. абитуриентов, то есть примерно в 1,7 раза меньше. В 2010-11 уч.г. в белорусских университетах числилось 442,9 тыс. студентов, в 2018-19 уч.г. соответственно 268,1 тыс., что в 1,6 раза меньше [1]. Таким образом, сегодня многие учебные заведения Республики Беларусь, и, в частности, ВУЗы, особенно специализирующиеся на подготовке специалистов по экономическим специальностям, вынуждены осу- ществлять свою деятельность в условиях дефицита абитуриентов и при этом параллельно обостряющейся конкуренции на рынке образовательных услуг. По экономическим специальностям в Беларуси готовят

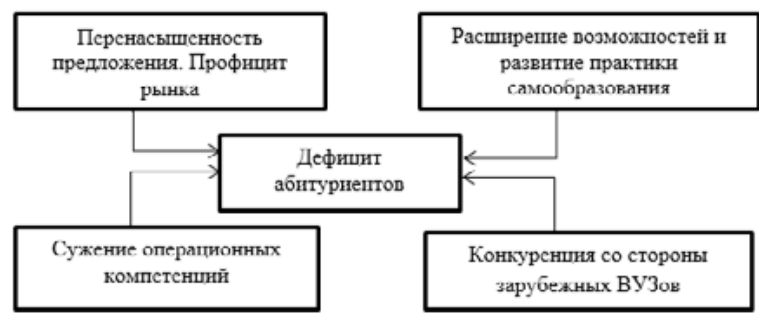

Pис. 1. Основные факторы, обуславливающие наличие дефичита абитуриентов в некоторых белорусских высших учебных заведениях 
на 7 столичных и на 18 областных экономических факультетах. Некоторые учебные заведения вынуждены значительно сократить набор, а в отдельных случаях, к сожалению, принимались решения о закрытии отдельных специальностей, на открытие и разработку которых в свое время затрачивались ресурсы. Помимо демографической ситуации в действие вступили рыночные факторы, сформировавшиеся в последние 5-10 лет, которые представлены на рисунке 1.

Перенасыщенность предложения. Профицит рынка. Рынок потребителей образовательных услуг (в форме высшего образования) сокращается не только за счет демографии, а также из-за отсутствия мотивации его получения. В первую очередь это связано с материальными факторами. Наличие экономического диплома не гарантирует соответствующую должность.

Сужение операционных компетенций. Повсеместная компьютеризация и внедрение интерактивных технологий во все процессы бизнес-администрирования обусловили делегирование целого ряда оформительских операций, не требующих глубоких системных знаний из прежних блоков компетенций специалистов с высшим образованием. В связи с этим сформировался рынок таких профессий, как оформитель отгрузочных документов или оператор по отгрузке, оформитель заказов, делопроизводитель, составитель отчетов или работник с базой данных, счетчик и т. п., где не требуется профильного высшего образования, что сокращает потенциальный рынок услуг получения высшего экономического образования.

Конкуренция со стороны зарубежных вузов. Рынок образовательных услуг все более подвержен тенденциям глобализации, как в региональном, так и в мировом масштабе. Так сегодня в Беларуси функционирует ряд филиалов зарубежных ВУЗов. Многие белорусы предпочитают получать высшее образование, особенно заочное, в российских, украинских, а в последнее время в польских и прибалтийских ВУЗах [1].
Расширение возможности и развитие практики самообразования. Белорусский рынок рабочей силы постепенно втягивается в общепринятую мировую тенденцию доминирования фактических умений и навыков сотрудника над его «экономическим» дипломом. Интернет сегодня представляет огромный массив возможностей для получения знаний в разных сферах. Например, уже сегодня во многих отечественных IT-компаниях работают люди со средним школьным образованием, при этом выполняющие серьезные, а главное высокооплачиваемые проекты.

Таким образом, белорусские ВУЗы оказались в сложной ситуации, когда плотность конкурентного поля увеличивается, а потенциальный массив студентов ограничен. Количество обучающихся иностранных студентов не решит данную проблему. Процент обучающихся студентов составляет около 7. Больше всего молодежи приехало из Туркменистана $(43,5 \%$ от общего числа студентов-иностранцев), за ними идут китайцы $(10,3 \%)$, россияне $(8,8 \%)$ и иранцы $(5,9 \%)$ [2]. Следует учесть, что поступление студентов из Туркменистана ограничено с 2019 г. и в Беларуси и оставлен только БГУ (Белорусский государственный университет), диплом которого будет признаваться в Туркменистане. Все это обуславливает необходимость оперативного поиска и реализации новых, не стандартных решений, которые должны быть направлены на выделение «легенды» ВУЗа и конкретных учебных предложений из общего информационного поля стратегий продвижения основных конкурентов, то есть его позиционирование относительно конкурента. В этом направлении предлагаем использовать Интернет-маркетинг персональных компетенций, под которым понимаем комплекс мероприятий, направленных на привлечение абитуриентов в ВУЗ посредством развития и продвижения персональных конкурентных преимуществ преподавателей (уникальные знания, умения, навыки и опыт) в контексте параллельного позиционирования

Общая характеристика модели «4П» в рамках реализаџии ВУЗом мероприятий в сфере маркетинга персональных компетенций

\begin{tabular}{|l|l|}
\hline \multicolumn{1}{|c|}{ Направления продвижения } & \multicolumn{1}{|c|}{ Возможный вектор продвижения и позиционирования } \\
\hline Предмет (специальность) & $\begin{array}{l}\text { Актуальность и перспективность изучаемой дисциплины, повсеместность ее распро- } \\
\text { странения и важность изучения, широта применения на внутреннем и внешнем рынке } \\
\text { рынка. Ключевые блоки, приоритетные аспекты, эмоционально-воодушевляющее } \\
\text { примеры }\end{array}$ \\
\hline Преподаватель & $\begin{array}{l}\text { Степень, звание, сертификаты и пр., презентация личных умений и навыков, реализо- } \\
\text { ванные проекты, бизнес-опыт, портфель кейсов, принципы и методика преподавания, } \\
\text { форма и методы обратной связи со студентами, кредо, девиз }\end{array}$ \\
\hline Практическая значимость & $\begin{array}{l}\text { Сфера решаемых задач, конкретные применения в бизнесе, администрировании и др., } \\
\text { требования работодателей, примеры умений и навыков, эффективность и значимость } \\
\text { при решении повсеместных хозяйственных задач, широта инструментария и диф- } \\
\text { ференциция, как средств, так и направлений обучения, используемое программное } \\
\text { обеспечение и средства Интернет }\end{array}$ \\
\hline Потенциальная полезность & $\begin{array}{l}\text { Должности, профессии и сферы деятельности, где требуется или применимо полу- } \\
\text { ченное образование (предмет); возможности карьерного роста и повышения квалифи- } \\
\text { кации; опыт успешных выпускников. Применение, например, как на госслужбе, так и } \\
\text { в бизнсе или открытии своего дела. Получаемый широкий базис знаний, необходи- } \\
\text { мых для дальнейшего развития в любой сфере }\end{array}$ \\
\hline
\end{tabular}


потенциальной полезности и практической (карьерной) значимости предлагаемых учебных дисциплин с использованием средств и возможностей Интернета. В рамках сформулированной приоритетной задачи реализацию Интернет-маркетинга персональных компетенций автором предлагается осуществлять в векторе продвижения модели привлечения абитуриентов 4 «П». В таблице 1 представлена общая характеристика каждому из выделенных направлений.

Исходя из содержания таблицы 1, отметим, что, например, в рамках Интернет-маркетинга можно использовать:

- видеохостинги: проморолики о ВУЗе, специальности, кафедре; интерактивное видео лекций, практических занятий; презентационный отчет о практике, получаемом опыте и др.;

- социальные сети: модерирование групп кафедры, факультета; создание интернет-сообществ по профильным интересам; формирование и ведение блогов/журналов; обсуждение проблем и др.

При позиционировании специальностей, а также отдельных предметов рекомендуется делать акцент на их практической значимости: раскрывать практику, формы, аспекты и повсеместность использования при реализации конкурентных коммерческих проектов, отдельных функций и задач. Естественно, в продвижении образовательных услуг не существует универсальных рецептов, позволяющих рассчитывать на безусловное достижение поставленных целей или оправдание затрат на коммуникации. Необходимо стремиться максимально завлечь студентов в работу с социальными сетями. Нужен постепенный профессиональный эволюционный путь развития, а не формальная отписка о создании сайта или группы в соцсетях, которые никто и никогда не будет посещать.
В интерактивных видео с презентационными лекционными, практическими или обзорными занятиями акцент должен быть сделан на человеческий (преподавательский) фактор. Просто интерактивная лекция без персонифицированного личностного позиционирования, осуществляемого преподавателем, не достигнет поставленных мотивационных целей. Акцент в концепции маркетинга персональных компетенций делается именно на преподавателе, который олицетворяет собою соответствующие знания, умения и навыки, которым потенциальный абитуриент должен захотеть научиться и без личного участия которого, например, посредством самообучения, он не сможет добиться желаемого аналогичного результата. Общеизвестно, что наибольшим добровольным желанием обучения и восприятия любой другой информации человек начинает обладать тогда, когда он находит в обучающем определенный авторитет- ориентир для себя: карьерный, моральный, харизматично-ораторский и и т. д.

Конечно, реалии конкурентного рынка услуг получения высшего экономического образования, обуславливают ограниченную эффективность любых коммуникационных мероприятий и необходимость постоянного выделения ВУЗа среди аналогичных предложений. Тем не менее, систематическая реализация предложенной концепции интернет-маркетинга персональных компетенций, позволит учебному заведению, как минимум не затеряться среди конкурентов и находиться в активном тренде, стимулирующем не только привлечение абитуриентов, но и развитие ВУЗа в целом, что является залогом формирования будущей конкурентоспособности учебного заведения в стремительно трансформирующемся поле образования в целом и высшего экономического образования в частности.

\section{Список литературы}

1. Адукар [Электронный ресурс]. - Режим доступа: https://adukar.by/news/kolichestvo-studentov-

2. Иностранные студенты: кого берут и как выбирают [Электронный ресурс]. - Режим доступа: https://news. tut.by/society/554433.html

\section{References}

1. Adukar. Retrieved from https://adukar.by/news/kolichestvo-studentov-

2. Inostrannye studenty: kogo berut i kak vybiraiut. Retrieved from https://news.tut.by/society/554433.html

\section{Информация об авторе}

Лизакова Роза Алексеевна, канд. эконом. наук, доцент кафедры менеджмента и маркетинга, Барановичский государственный университет, Барановичи, Беларусь.
Information about the author

Roza A. Lizakova, Cand. Sci. (Econ.), associate professor at the Department of management and marketing, Baranovichi State University, Baranovichi, Belarus.
Информация об авторе

Лизакова Роза Алексеевна, экономика ӑслӑлӑхе̌н к-че̌, Барановичи патшалӑх университече̌н менеджмент тата маркетинг кафедрин доценче̌, Барановичи, Беларусь. 